\title{
Lower air temperature is associated with ambulance transports and death in Takamatsu area, Japan
}

\author{
Kazumi Dokai Mochimasu • Nobuyuki Miyatake • \\ Naoko Tanaka $\cdot$ Hiroshi Kinoshita
}

Received: 10 January 2014/ Accepted: 17 February 2014/Published online: 11 March 2014

(c) The Japanese Society for Hygiene 2014

\begin{abstract}
Objective The aim of this study was to investigate the linkage among ambulance transports, the number of death and air temperature in Takamatsu area, Japan.

Methods Monthly data of ambulance transports (total and acute disease) and the number of death from 2004 to 2012 were obtained from Fire Department Service in Takamatsu and Takamatsu city official website, Japan. Climate parameters for required period were also obtained from Japan Meteorological Agency. Population data in Takamatsu area were also used to adjust ambulance transports and the number of death. The linkage among ambulance transports, the number of death and climate parameters was evaluated by ecological analysis.

Results Total ambulance transports (/a hundred thousand people/day) and ambulance transports due to acute disease (/a hundred thousand people/day) were $12.3 \pm 0.9$ and $6.8 \pm 0.7$, respectively. The number of death (/a hundred thousand people/day) was $2.5 \pm 0.4$. By quadratic curve, ambulance transports due to acute disease and the number of death were significantly correlated with the parameters of air temperature. However, the number of death was the highest in January and the lowest in August.
\end{abstract}

K. D. Mochimasu

Department of Food Science, Mimasaka University,

Okayama 708-8511, Japan

K. D. Mochimasu $(\varangle) \cdot$ N. Miyatake

Department of Hygiene, Faculty of Medicine, Kagawa

University, Miki, Kagawa 761-0793, Japan

e-mail: dokai@med.kagawa-u.ac.jp

N. Tanaka $\cdot$ H. Kinoshita

Department of Forensic Medicine, Faculty of Medicine,

Kagawa University, Kagawa 761-0793, Japan
Conclusion Although higher air temperature was only associated with higher ambulance transports, lower air temperature was associated with both higher ambulance transports and the number death in Takamatsu area, Japan.

Keywords Air temperature - Ambulance transports . Acute disease - Quadratic curve

\section{Introduction}

It is well known that higher air temperature is closely associated with health problem such as heat stroke. We have previously reported that higher air temperature was closely associated with higher ambulance transports due to heat stroke by ecological study $[1,2]$. In Takamatsu area, located on the northern shore of Shikoku Island, Japan, changes in mean air temperature were estimated $1.8^{\circ} \mathrm{C}$ for 50 years [3], and higher air temperature was closely linked to higher total ambulance transports by using monthly data [4]. Taken together, higher air temperature and its related health problems have become public health challenge in Takamatsu area as well as all over Japan.

In turn, lower air temperature is also associated with severe health problems [5-10]. We have also reported that lower air temperature was associated with higher frequency of ambulance transports in Sakata area located in northern part (Tohoku area) and cold climate area in Japan [11]. However, our hypothesis is that the number of death may not be directly associated with the number of ambulance transports, and the linkage among ambulance transports due to acute disease, the number of death and lower air temperature was not fully discussed in all over Japan. Therefore, in this pilot study, we evaluated the linkage among ambulance 
transports, the number of death and air temperature in Takamatsu area, Japan, which has a humid subtropical climate, by ecological study.

\section{Method}

\section{Study area}

Takamatsu area, Kagawa prefecture, Japan, which includes Takamatsu city, Miki-cho and Ayagawa-cho, is on the northern shore of Shikoku Island (in a temperate zone area). The population of Kagawa prefecture is approximately 1,000,000 and approximately 480,000 people are situated on the Takamatsu area. Currently, several public offices of Shikoku district are located in Takamatsu city. Although the surrounds of Takamatsu had been used primarily as paddy fields for agriculture, recently they have undergone rapid changes, developing into residential and/ or commercial areas. The area's emergency medical services are managed by Fire Department Service in Takamatsu, Japan.

\section{Ambulance transports}

Monthly incidence data of ambulance transports (total and acute disease) in Takamatsu area (Takamatsu city, Mikicho and Ayagawa-cho) were obtained from Fire Department Service in Takamatsu from 2004 to 2012 for 9 years [12]. We used total number of ambulance transports and the number of acute disease that excluded the number of other ambulance transports, i.e., traffic accidents, fire accidents and injuries [13] for this analysis.

\section{Death}

Monthly incidence data of death in Takamatsu city was also obtained from Takamatsu city official website for same period [14].

\section{Population}

To adjust for population, annual population data in Takamatsu area (Takamatsu city, Miki-cho and Ayagawa-cho) and monthly population data in Takamatsu city for required period were also used for the analysis $[12,15]$.

\section{Climate parameters}

Monthly climate parameters in Takamatsu area for the required periods were obtained from Japan Meteorological Agency [16]. Mean air temperature $\left({ }^{\circ} \mathrm{C}\right)$, mean of the highest air temperature $\left({ }^{\circ} \mathrm{C}\right)$, mean of the lowest air temperature $\left({ }^{\circ} \mathrm{C}\right)$, the highest air temperature $\left({ }^{\circ} \mathrm{C}\right)$, the lowest air temperature $\left({ }^{\circ} \mathrm{C}\right)$, mean humidity $(\%)$, the lowest humidity $(\%)$ and daylight hours (h/month) were used for analysis.

Statistical analysis

Data are expressed as mean \pm standard deviation (SD) values. Comparisons among more than three groups were performed by ANOVA and Scheffe's $F$ test. $p<0.05$ was considered to indicate statistical significance. In addition, quadratic curve was applied to the link between ambulance transports, the number of death and climate parameters.

Ethics

The protocol of the study was approved by the Ethics Committee of the Mimasaka University, Okayama, Japan.

\section{Results}

Data of ambulance transports (total and acute disease), the number of death and climate parameters from 2004 to 2012 in Takamatsu area were summarized in Table 1. Ambulance transports (/a hundred thousand people/day) and the number of death (/a hundred thousand people/day) were $12.3 \pm 0.9$ (total ambulance transports), $6.8 \pm 0.7$ (ambulance transports due to acute disease) and $2.5 \pm 0.4$ (death), respectively. Mean air temperature was $16.8 \pm 8.1$ (4.1-30.4) $\left({ }^{\circ} \mathrm{C}\right)$.

Comparison of ambulance transports and the number of death as classified by month groups are shown in Table 2. The number of death in January was significantly higher than that in other months (except February). The number of death in February was also significantly higher than that in June, July, August and September. Thus, the number of death in January was the highest and that in August was the lowest. However, there were no significant differences between total ambulance transports and ambulance transports due to acute disease among months. The number of total ambulance transports and ambulance transports due to acute disease was the highest in December and that was the lowest in June, but not at a significant level (Table 2).

We estimated the relation between ambulance transports (/a hundred thousand people/day) and climate parameters by quadratic curve (Table 3 ). Total ambulance transports were weakly associated with mean air temperature, mean of the highest air temperature, mean of the lowest air temperature and the lowest air temperature. Ambulance transports due to acute disease were also associated with mean air temperature, mean of the highest air temperature 
Table 1 Profiles of climate parameters and ambulance transports from 2004 to 2012 in Takamatsu area, Japan

\begin{tabular}{|c|c|c|c|}
\hline & Mean $\pm \mathrm{SD}$ & Minimum & Maximum \\
\hline Number of month & 108 & & \\
\hline $\begin{array}{l}\text { Mean air temperature } \\
\left({ }^{\circ} \mathrm{C}\right)\end{array}$ & $16.8 \pm 8.1$ & 4.1 & 30.4 \\
\hline $\begin{array}{l}\text { Mean of the highest air } \\
\text { temperature }\left({ }^{\circ} \mathrm{C}\right)\end{array}$ & $21.1 \pm 8.2$ & 7.7 & 34.7 \\
\hline $\begin{array}{l}\text { Mean of the lowest air } \\
\text { temperature }\left({ }^{\circ} \mathrm{C}\right)\end{array}$ & $12.9 \pm 8.4$ & 0.6 & 26.6 \\
\hline $\begin{array}{l}\text { The highest air } \\
\text { temperature }\left({ }^{\circ} \mathrm{C}\right)\end{array}$ & $26.5 \pm 7.8$ & 10.0 & 37.8 \\
\hline $\begin{array}{l}\text { The lowest air } \\
\text { temperature }\left({ }^{\circ} \mathrm{C}\right)\end{array}$ & $8.3 \pm 8.6$ & -3.4 & 24.2 \\
\hline Mean humidity (\%) & $65.2 \pm 5.3$ & 54.0 & 76.0 \\
\hline The lowest humidity (\%) & $24.3 \pm 8.5$ & 6.0 & 41.0 \\
\hline Daylight hours (h/month) & $171.0 \pm 38.1$ & 110.0 & 275.6 \\
\hline $\begin{array}{l}\text { Total ambulance } \\
\text { transports }\end{array}$ & $1,528.8 \pm 190.3$ & $1,105.0$ & $2,021.0$ \\
\hline $\begin{array}{l}\text { Total ambulance } \\
\text { transports (/a hundred } \\
\text { thousand people/day) }\end{array}$ & $10.8 \pm 1.2$ & 7.9 & 13.9 \\
\hline $\begin{array}{l}\text { Ambulance transports } \\
\text { due to acute disease }\end{array}$ & $847.9 \pm 124.9$ & 597.0 & $1,176.0$ \\
\hline $\begin{array}{l}\text { Ambulance transports } \\
\text { due to acute disease (/a } \\
\text { hundred thousand } \\
\text { people/day) }\end{array}$ & $6.0 \pm 0.8$ & 4.2 & 8.2 \\
\hline Death & $305.6 \pm 58.3$ & 179.0 & 479.0 \\
\hline $\begin{array}{l}\text { Death (/a hundred } \\
\text { thousand people/day) }\end{array}$ & $2.5 \pm 0.4$ & 1.7 & 3.9 \\
\hline
\end{tabular}

( $r=0.463, p<0.0001$ ) (Fig. 1), mean of the lowest air temperature, the highest air temperature, the lowest air temperature and the lowest humidity. The correlation coefficients between ambulance transports due to acute disease and the mean of the highest air temperature were the highest among variables. From the regression line, a $22.3{ }^{\circ} \mathrm{C}$ in mean of the highest air temperature was
Table 2 Comparison of ambulance transports as classified by month in Takamatsu area, Japan

\begin{tabular}{lllll}
\hline Month & Total & $\begin{array}{l}\text { Acute } \\
\text { disease }\end{array}$ & $\begin{array}{l}\text { Acute } \\
\text { disease } \\
\text { total }\end{array}$ & Death \\
& Mean $\pm \mathrm{SD}$ & Mean $\pm \mathrm{SD}$ & $(\%)$ & Mean $\pm \mathrm{SD}$ \\
\hline January & $11.1 \pm 1.0$ & $6.5 \pm 0.7$ & 58.3 & $3.3 \pm 0.3$ \\
February & $10.8 \pm 1.1$ & $6.2 \pm 0.7$ & 57.3 & $2.8 \pm 0.3$ \\
March & $11.0 \pm 0.9$ & $6.2 \pm 0.7$ & 56.3 & $2.6 \pm 0.1 \mathrm{a}$ \\
April & $10.4 \pm 0.9$ & $5.6 \pm 0.5$ & 53.5 & $2.5 \pm 0.1 \mathrm{a}$ \\
May & $10.3 \pm 1.2$ & $5.6 \pm 0.6$ & 54.2 & $2.5 \pm 0.3 \mathrm{a}$ \\
June & $10.2 \pm 1.0$ & $5.5 \pm 0.6$ & 54.2 & $2.2 \pm 0.2 \mathrm{ab}$ \\
July & $10.9 \pm 1.2$ & $6.1 \pm 0.8$ & 55.4 & $2.2 \pm 0.2 \mathrm{ab}$ \\
August & $11.2 \pm 1.6$ & $6.3 \pm 1.0$ & 55.8 & $2.1 \pm 0.2 \mathrm{ab}$ \\
September & $10.6 \pm 1.3$ & $5.8 \pm 0.8$ & 55.3 & $2.2 \pm 0.2$ \\
& & & & $\mathrm{ab}$ \\
October & $10.6 \pm 1.0$ & $5.7 \pm 0.7$ & 53.6 & $2.3 \pm 0.2 \mathrm{a}$ \\
November & $10.9 \pm 1.0$ & $5.9 \pm 0.7$ & 54.5 & $2.5 \pm 0.2 \mathrm{a}$ \\
December & $11.9 \pm 1.2$ & $6.7 \pm 0.8$ & 55.7 & $2.4 \pm 0.2 \mathrm{a}$ \\
\hline
\end{tabular}

$N=9$

/a hundred thousand people/day

a: $p<0.05$ vs January

b: $p<0.05$ vs February

corresponded to a change point of ambulance transports due to acute disease.

The relationship between the number of death (/a hundred thousand people/day) and climate parameters by quadratic curve was also evaluated (Table 4). The number of death was significantly correlated with climate parameters (except daylight hours). The correlation coefficients between the number of death and the mean of the highest air temperature was also the highest among variables $(r=0.703, p<0.0001)$ (Fig. 2).

Finally, by simple correlation analysis, the number of death was significantly correlated with ambulance

Table 3 Approximation by quadratic curve between ambulance transports (/a hundred thousand people/day) and climate parameters

\begin{tabular}{|c|c|c|c|c|c|}
\hline & \multicolumn{4}{|l|}{ Total } & \multirow{2}{*}{$\begin{array}{l}\text { Acute disease } \\
\text { Quadratic curve ( } Y \text { : ambulance transports, } X \text { : climate parameters) }\end{array}$} \\
\hline & $r$ & $p$ & $r$ & $p$ & \\
\hline Mean air temperature $\left({ }^{\circ} \mathrm{C}\right)$ & 0.303 & 0.0065 & 0.451 & $<0.0001$ & $Y=0.006 X^{2}-0.227 X+7.692$ \\
\hline Mean of the highest air temperature $\left({ }^{\circ} \mathrm{C}\right)$ & 0.310 & 0.0049 & 0.463 & $<0.0001$ & $Y=0.006 X^{2}-0.267 X+8.643$ \\
\hline Mean of the lowest air temperature $\left({ }^{\circ} \mathrm{C}\right)$ & 0.285 & 0.0115 & 0.429 & $<0.0001$ & $Y=0.006 X^{2}-0.174 X+6.873$ \\
\hline The highest air temperature $\left({ }^{\circ} \mathrm{C}\right)$ & 0.232 & 0.0554 & 0.370 & 0.0004 & $Y=0.004 X^{2}-0.217 X+8.894$ \\
\hline The lowest air temperature $\left({ }^{\circ} \mathrm{C}\right)$ & 0.338 & 0.0017 & 0.449 & $<0.0001$ & $Y=0.006 X^{2}-0.132 X+6.238$ \\
\hline Mean humidity (\%) & 0.133 & 0.3896 & 0.129 & 0.4172 & \\
\hline The lowest humidity (\%) & 0.223 & 0.0680 & 0.271 & 0.0180 & $Y=-0.002 X^{2}+0.107 X+4.658$ \\
\hline Daylight hours (h/month) & 0.075 & 0.7426 & 0.142 & 0.3450 & \\
\hline
\end{tabular}

Bold values are statistically significant $(p<0.05)$ 
transports due to acute disease in Takamatsu area, Japan $(r=0.418, p<0.0001)$.

\section{Discussion}

In this study, we firstly evaluate the linkage among ambulance transports, the number of death and air temperature in Takamatsu area, Japan. Lower air temperature was closely associated with higher ambulance transports and death. However, the higher air temperature was associated with ambulance transports, but not the number of death.

Ou et al. [5] reported that a subtropical city Guangzhou showed a clear seasonal pattern in mortality, with a shaper spike in winter. Wanitschek et al. [6] reported that the average temperature increase of $7.5{ }^{\circ} \mathrm{C}$ from the cold to the warm winter was associated with a decrease in acute coronary angiographies. Cancer mortality, which was more

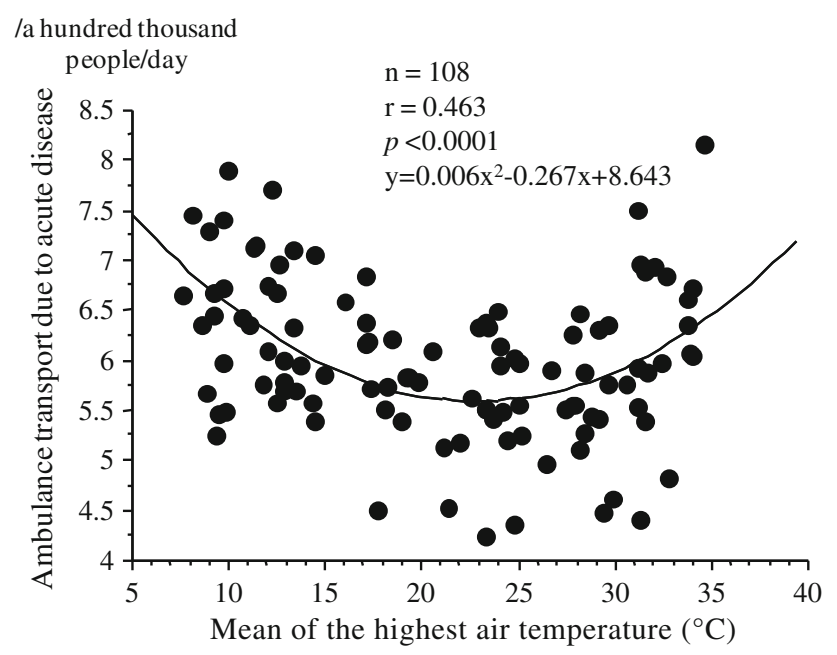

Fig. 1 Estimation of the relation between mean of the highest air temperature and ambulance transport due to acute disease by quadratic curve in Takamatsu area, Japan remarkably in elderly, was also associated with cold air temperatures [7]. Low air temperatures were significantly associated with intestinal infectious diseases, respiratory diseases, endocrine, nutritional and metabolic diseases [8]. Also in Japan, Tanaka et al. [9] evaluated the mortality due to ischemic heart disease and cerebrovascular disease among Okinawa and Osaka area, and found that lower mortality from ischemic heart disease and cerebrovascular disease in Okinawa is affected, at least in part, by Okinawa's warm winter. Abe et al. [10] showed the cold air temperature is related to an increased risk of asthma in adults.

In this study, lower air temperature was closely associated with higher ambulance transports and higher incidence of death in Takamatsu area. However, higher air temperature was clearly correlated with higher ambulance transports as previous reports, but not obviously correlated with higher death. Therefore, there was a discrepancy between higher air temperature-related ambulance transports and the number of death, suggesting that higher ambulance transports may not be directly related to death. It is well known that higher ambulance transports due to heat stroke are closely linked to higher air temperature [1, 2]. However, in fact, the number of death due to heat stroke in Japan was reported to be only 1,718 subjects in 2010 [17]. In addition, in Japan, the first factor of death is cancer, and then followed by heart disease, pneumonia and cerebral vascular disease (CVD) [18], especially pneumonia increased remarkably. It is well known that these factors are associated with low air temperature [6-9]. Therefore, these factors may affect the relationship between low air temperature and the number of death in Takamatsu area as well as all over Japan. Global warming and its related health problem have become public challenge in Japan as well as in the world. Taken together, when we estimate the changes in ambulance transports and the number of death in future, the effect of low air temperature on ambulance transports and death should be taken into account. From this pilot study, the number of death may reduce, in turn,

Table 4 Approximation by quadratic curve between death (/a hundred thousand people/day) and climate parameters

\begin{tabular}{llll}
\hline & $r$ & $p$ & Quadratic curve $(Y$ : death, $X$ : climate parameters) \\
\hline Mean air temperature $\left({ }^{\circ} \mathrm{C}\right)$ & 0.701 & $<\mathbf{0 . 0 0 0 1}$ & $Y=0.001 X^{2}-0.077 X+3.289$ \\
Mean of the highest air temperature $\left({ }^{\circ} \mathrm{C}\right)$ & 0.703 & $<\mathbf{0 . 0 0 0 1}$ & $Y=0.001 X^{2}-0.085 X+3.602$ \\
Mean of the lowest air temperature $\left({ }^{\circ} \mathrm{C}\right)$ & 0.698 & $<\mathbf{0 . 0 0 0 1}$ & $Y=0.001 X^{2}-0.067 X+3.006$ \\
The highest air temperature $\left({ }^{\circ} \mathrm{C}\right)$ & 0.697 & $<\mathbf{0 . 0 0 0 1}$ & $Y=0.001 X^{2}-0.086 X+3.944$ \\
The lowest air temperature $\left({ }^{\circ} \mathrm{C}\right)$ & 0.674 & $<\mathbf{0 . 0 0 0 1}$ & $Y=0.001 X^{2}-0.055 X+2.725$ \\
Mean humidity $(\%)$ & 0.513 & $<\mathbf{0 . 0 0 0 1}$ & $Y=-0.001 X^{2}+0.12 X-0.203$ \\
The lowest humidity $(\%)$ & 0.305 & $\mathbf{0 . 0 0 5 9}$ & $Y=-0.001 X^{2}+0.05 X+2.074$ \\
Daylight hours (h/month) & 0.208 & 0.0973 &
\end{tabular}

Bold values are statistically significant $(p<0.05)$ 


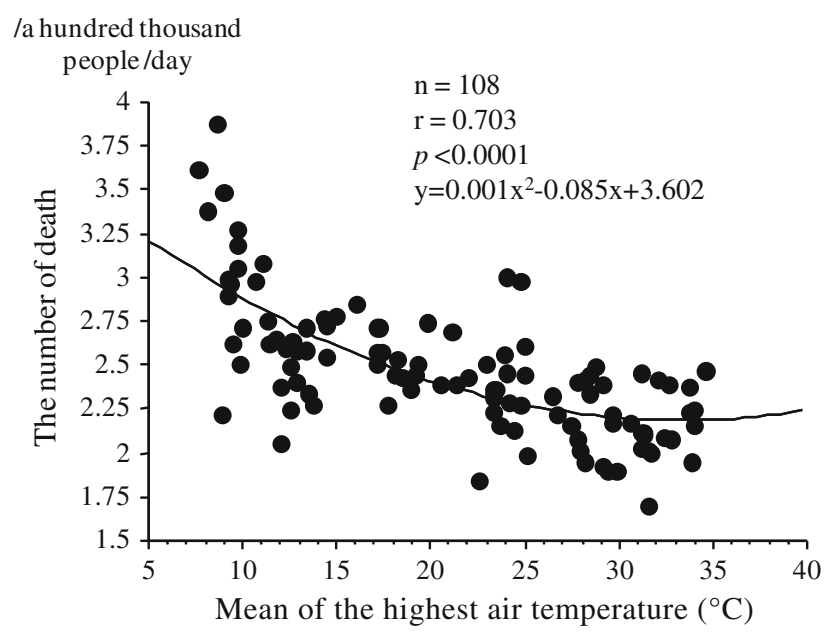

Fig. 2 Estimation of the relation between mean of the highest air temperature and the number of death by quadratic curve in Takamatsu city, Japan

changes in the number of ambulance transports could not be estimated clearly. Nevertheless, it seems reasonable to suggest that simply dealing with low air temperature effect, i.e., innovation of the thermal energy metabolism in cities and individual and group coping [19] with low air temperatures may be required in Takamatsu area as well as all over Japan.

Potential limitations still remain in this study. First, we used an ecological study. The linkage among ambulance transports, the number of death and air temperatures, which was noted in this study, may not apply for the link among individuals. Second, detailed daily and individual (i.e., age and sex) data of ambulance transports and death could not be obtained and analyzed in this study. Therefore, these factors may affect the relationship between low air temperature and the number of death in Takamatsu area as well as all over Japan.

Conflict of interest The authors declare no conflict of interests.

\section{References}

1. Miyatake N, Sakano N, Murakami S. The relation between ambulance transports stratified by heat stroke and air temperature in all 47 prefectures of Japan in August 2009: ecological study. Environ Health Prev Med. 2012;17:77-80.

2. Murakami S, Miyatake N, Sakano N. Changes in air temperature and its relation to ambulance transports due to heat stroke in all 47 prefectures of Japan. J Prev Med Public Health. 2012;45: 309-15.
3. Miyatake N, Sakano N, Murakami S, Suna S, Suzue T, Hirao T. Comparison of the changes in temperatures among rural, urban and metropolitan areas around the Inland Sea in Japan. Environ Monit Assess. 2011;181:525-30.

4. Miyatake N, Nakao M, Sakano N, Suna S, Suzue T, Hirao T. Higher temperatures were closely associated with higher ambulance transports in Takamatsu area, Japan. J Environ Prot. 2011;2:72-5.

5. Ou CQ, Song YF, Yang J, Chau PY, Yang L, Chen PY, et al. Excess winter mortality and cold temperatures in a subtropical city, Guangzhou, china. PLoS One. 2013;8(10):e77150.

6. Wanitschek M, Ulmer H, Sussenbacher A, Dorler J, Pachinger O, Alber HF. Warm winter is associated with low incidence of ST elevation myocardial infarctions and less frequent acute coronary angiographies in an alpine country. Herz. 2013;38:163-70.

7. Gomez-Acebo I, Llorca J, Dierssen T. Cold-related mortality due to cardiovascular diseases, respiratory diseases and cancer: a case-crossover study. Public Health. 2013;127:252-8.

8. Xu Z, Hu W, Su H, Turner LR, Ye X, Wang J, et al. Extreme temperatures and paediatric emergency department admissions. J Epidemiol Community Health 2014;68:304-11.

9. Tanaka H, Shinjo M, Tsukuma H, Kawazuma Y, Shimoji S, Kinoshita N, et al. Seasonal variation in mortality from ischemic heart disease and cerebrovascular disease in Okinawa and Osaka: the possible role of air temperature. J Epidemiol. 2000;10:392-8.

10. Abe T, Tokuda Y, Ohde S, Ishimatsu S, Nakamura T, Birrer RB. The relationship of short-term air pollution and weather to ED visits for asthma in Japan. Am J Emerg Med. 2009;27:153-9.

11. Miyatake N, Hirao T, Sakano N, Tanaka N, Kinoshita H. Lower air temperature was associated with higher ambulance transports in Sakata area, Yamagata prefecture, Japan. Open J Epidemiol. 2013;3:220-3.

12. Fire Department Service in Takamatsu, Japan: Annual report. http://www.city.takamatsu.kagawa.jp/10991.html. Accessed 7 Nov 2013

13. Fire and Disaster Management Agency, Japan: Classification of ambulance transports. http://aeml.umin.ac.jp/hou/0690.html. Accessed 13 Nov 2013

14. Takamatsu city official web site: Monthly death in Takamatsu city, Japan [Cited 2013 November 13] http://www.city.taka matsu.kagawa.jp/1578.html. Accessed 13 Nov 2013

15. Takamatsu city official web site: Monthly change in population in Takamatsu city, Japan. http://www.city.takamatsu.kagawa.jp/ 17802.html. Accessed 13 Nov 2013

16. Japan Meteorological Agency, Japan: Monthly climate change parameters in Takamatsu area, Japan. http://www.data.jma.go.jp/ obd/stats/etrn/index.php?prec_no=72\&block_no=47891\&year= $\&$ month $=\&$ day $=\&$ view $=$. Accessed 13 Nov 2013

17. Ministry of Health, Labour and Welfare, Japan: Number of death due to heat stroke in 2010. http://www.mhlw.go.jp/stf/houdou/ 2r9852000001g7ag.html. Accessed 13 Nov 2013

18. Ministry of Health, Labour and Welfare, Japan: Vital Statistics of Japan. http://www.mhlw.go.jp/toukei/saikin/hw/jinkou/kaku tei12/d1/10_h6.pdf. Accessed 24 Jan 2014

19. Suzue T, Hoshikawa Y, Nishihara S, Fujikawa A, Miyatake N, Sakano N, et al. The new school absentees reporting system for pandemic influenza $\mathrm{A} / \mathrm{H} 1 \mathrm{~N} 1$ infection in Japan. PLoS One. 2012;7(2):e30639. 